\title{
Representação social da violência doméstica contra a mulher entre discentes de enfermagem
}

\author{
Camila Daiane Silva*a, Vera Lúcia de Oliveira Gomes ${ }^{\mathrm{a}}$
}

${ }^{a}$ Escola de Enfermagem. Universidade Federal do Rio Grande. Rio Grande, RS, Brasil.

\section{Histórico do Artigo \\ Recebido em: 20/07/2017 \\ Aceito em: 06/09/2017 \\ Palavras-chave: \\ Violência contra a \\ mulher \\ Estudantes de \\ enfermagem \\ Programas de graduação em enfermagem \\ Enfermagem}

Keywords:

Violence against women

Nursing students

Undergraduate nursing

programs

Nursing

\begin{abstract}
RESUMO
Objetiva-se identificar a estrutura e o conteúdo da representação acerca da violência doméstica contra a mulher entre discentes de enfermagem. Colheram-se os dados entre agosto e novembro de 2014 por meio de evocações livres; para o tratamento, utilizou-se o software EVOC e análise de similitude. Aprovação sob parecer de nº88/2014. Participaram 132 discentes. O núcleo central é formado pelos termos covardia, desrespeito, violência, violência física e dor. Na primeira periferia constam os termos medo e submissão e na segunda, vergonha. Na zona de contraste consta os termos sofrimento, tristeza, machismo, crime, impunidade e maria da penha. Trata-se de uma representação com conotação negativa, estruturada, pois contém os elementos imagéticos, atitudinais e conceituais, fundamentada no conhecimento do senso comum e, principalmente, reificado. Esse evidencia, possivelmente entre as discentes das séries finais, o rompimento com a naturalização da ocorrência da violência.
\end{abstract}

Social representation of domestic violence against women among nursing students

\section{ABSTRACT}

Aimed to identify the structure and content of the representation about domestic violence against women among nursing students. The data were collected between August and November of 2014 by means of free evocations, for the treatment was used EVOC software and similarity analysis. Approval under the opinion of $n^{\circ} 0888 / 2014$. There were 132 students. The central nucleus is formed by the terms cowardice, disrespect, violence, physical violence and pain. In the first periphery are the terms fear and submission and in the second, shame. In the zone of contrast there is the terms suffering, sadness, machismo, crime, impunity and Maria of the rock. It is a representation with negative connotation, structured because it contains the imaginary, attitudinal and conceptual elements, based on the knowledge of common sense and, mainly, reified. This evidence, possibly among the students of the final series, the rupture with the naturalization of the occurrence of violence.

\section{Introdução}

A violência doméstica contra a mulher (VDCM) pode ser visualizada em diferentes cenários e ocorrer nas mais diversas partes do mundo. Dados divulgados pela Organização Mundial da Saúde (OMS) revelam que a violência perpetrada pelo parceiro íntimo é a forma mais comum, atingindo cerca de $30 \%$ das mulheres em todo o mundo (1). O Mapa da Violência, em 2012, evidenciou que no ranking internacional de homicídios de mulheres, entre os anos de 2006 e 2010, os Estados Unidos da América (EUA) ocupou o $24^{\circ}$ lugar e a França o $68^{\circ}$ (2). O Brasil ficou na sétima colocação, apesar da existência da Lei 11.340, conhecida como Maria da Penha (LMP), a qual visa coibir a violência doméstica e familiar contra a mulher (3).

\footnotetext{
* Autor correspondente: camilad.silva@yahoo.com.br (C. D. Silva)
} 
Somente em 2014, a central de atendimento à mulher (ligue 180), registrou 52.957 denúncias de violência contra a mulher, das quais 51,68\% referiam-se à violência física, $31,81 \%$ psicológica, $9,68 \%$ moral, $2,86 \%$ sexual, $1,94 \%$ patrimonial, $1,76 \%$ cárcere privado e $0,26 \%$ tráfico. A central verificou que a violência ocorre desde o início do relacionamento e entre um a cinco anos, a maioria das vítimas possuem filhos que presenciam a violência (4).

Apesar de expressivos esses índices, acredita-se que muitos são os casos de VDCM que permanecem restritos ao lar. Por vezes, amigos, familiares, vizinhos e a própria vítima naturalizam a violência, não a reconhecendo como tal. Na maioria das vezes, apenas os casos de violência que requerem atendimento de saúde extrapolam o espaço familiar. No entanto, poucos desses casos são reconhecidos e abordados como consequências da violência (5). Nesse sentido, os profissionais de saúde, em especial enfermeiros, devem estar preparados para prestar a assistência às vítimas, pois podem ser os primeiros a quem as mulheres recorrem em busca de apoio.

Estudos apontam que os profissionais se sentem despreparados para atuarem em situações de violência, uma vez que a temática durante a graduação foi abordada superficialmente, configurando uma grande preocupação $(5,6)$. Além dessas lacunas, as crenças, mitos e representações podem constituir entraves para uma assistência de enfermagem integral à vítima.

Nesse sentido, destaca-se o papel social que as instituições de Ensino Superior têm de formar profissionais capazes de atuarem com responsabilidade e compromisso sobre os problemas e situações de saúde/doença prevalentes em nível nacional (7). Dessa forma, as diferentes vivências acadêmicas oportunizadas durante o curso de graduação em enfermagem podem influenciar na representação social dos estudantes.

Acredita-se que as representações sociais são um princípio gerador de tomada de posição em um conjunto de relações sociais e organiza processos simbólicos que interferem em tais relações (8). Assim, optou-se por investigar qual a representação social acerca da violência doméstica contra a mulher entre discentes do curso de graduação em enfermagem? Teve-se como objetivo identificar a estrutura e o conteúdo dessa representação.

\section{Método}

Pesquisa qualitativa, descritiva, fundamentada na Teoria das Representações Social (TRS). Realizou-se o estudo em um curso de graduação em enfermagem, de uma universidade federal, localizada ao extremo sul do Brasil. Participaram todos os discentes de enfermagem das três séries iniciais e finais, justifica-se essa escolha por acreditar-se que os ingressantes carregam o conhecimento do senso comum, já os formandos construíram, ao longo do curso de graduação, o conhecimento reificado, que contribui para a modificação da representação social. Foram excluídos os que faltaram à aula no período de coleta.

Colheram-se os dados entre agosto e novembro de 2014. Inicialmente, aplicou-se um questionário com questões referentes à situação pessoal, social e acadêmica. Em seguida, desenvolveu-se a técnica de evocações ou associação livre. Por meio dessa, é possível apreender a percepção da realidade, a partir de um campo semântico já existente, o qual é concreto, imagético e se organiza em torno de elementos simbólicos simples (9). Para tanto, solicitou-se aos participantes que, frente ao termo indutor "violência doméstica contra a mulher", associassem as primeiras cinco palavras ou expressões e determinassem sua positividade, negatividade ou neutralidade com os sinais,+- ou 0 , respectivamente. 
Os dados foram tratados pelo software Ensemble de Programmes Pemettant L'Analyse des Evocations (EVOC) versão 2005 e pela análise de similitude. O programa foi criado por Pierre Vergès e tem como critérios a frequência e a ordem de aparição dos termos evocados, por meio dele é possível construir o quadro de quatro casas, constituído pelos elementos centrais, de primeira e segunda periferias e de contraste (8).

Com os resultados da etapa anterior, aplicou-se a análise de similitude proposta por Claude Flament em 1986, que tem por base o cálculo de conexidade entre os elementos da representaçã (8). Dessa forma, calcularam-se as coocorrências dos termos constantes no quadro de quatro casas, considerando apenas os sujeitos que evocaram pelo menos dois termos do referido quadro. Elaborou-se a tabela de coocorrências para calcular o índice de similitude, construindo assim a árvore máxima. A pesquisa respeitou as recomendações da Resolução 466/2012, sendo aprovada pelo Comitê de Ética em Pesquisa na Área da Saúde, sob parecer de nº 088/2014.

\section{Resultados e discussão}

Dos 132 discentes de enfermagem, 71 eram das séries iniciais e 61 das finais. Quanto ao sexo, nas séries inicias, havia 62 mulheres e nove homens; nas séries finais, 56 mulheres e cinco homens. A idade variou de 17 a 50 anos, predominando entre as séries iniciais a faixa etária dos 17 a 20 anos (31) e entre as séries finais a faixa dos 21 a 30 anos (52). A maioria dos discentes de ambas as séries possuíam companheiro e não tinham filhos.

O corpus formado pelas evocações dos 132 discentes de enfermagem frente ao termo indutor "violência doméstica contra a mulher", totalizou 658 palavras sendo 134 diferentes. Em uma escala de um a cinco, a média das ordens médias de evocação (O.M.E) foi três, a frequência mínima, quinze e a frequência média, 23. A análise desse conjunto de dados resultou no quadro de quatro casas (Quadro 1).

O núcleo central elucida a natureza e a relação do grupo com o objeto social, bem como as normas e valores que regiam a sociedade naquele momento. Localizado no quadrante superior esquerdo o núcleo central contém os termos com alta frequência, prontamente evocados e mais significativos para as participantes (10). Neste estudo, a provável centralidade da representação social dos discentes de enfermagem contém os termos covardia, desrespeito, violência, violência-física e dor. Destaca-se que covardia foi o mais frequente e violência o mais prontamente evocado.

Quadro 1. Quadro de quatro casas da representação social dos discentes de enfermagem acerca da violência doméstica contra a mulher. Rio Grande, RS, 2014.

\begin{tabular}{|c|c|c|c|c|c|c|}
\hline O.M.E. & & & & & & \\
\hline $\begin{array}{l}\text { Freq. } \\
\text { Méd. }\end{array}$ & Termo evocado & Freq. & O.M.E. & Termo evocado & Freq. & O.M.E \\
\hline \multirow{5}{*}{$\geq 23$} & Covardia (-) & 29 & 2,138 & Medo (-) & 40 & 3,175 \\
\hline & Desrespeito (-) & 28 & 2,464 & Submissão (-) & 23 & 3,130 \\
\hline & Violência (-) & 27 & 1,889 & & & \\
\hline & Violência-física (-) & 26 & 2,577 & & & \\
\hline & Dor (-) & 24 & 2,167 & & & \\
\hline \multirow{6}{*}{$<23$} & $\begin{array}{l}\text { Sofrimento (-) } \\
\text { Sof }\end{array}$ & $\overline{22}$ & 2,727 & Vergonha (-) & 15 & 3,333 \\
\hline & Tristeza (-) & 19 & 2,632 & & & \\
\hline & Machismo (-) & 17 & 3,000 & & & \\
\hline & Crime (-) & 15 & 2,533 & & & \\
\hline & Impunidade (-) & 15 & 2,733 & & & \\
\hline & Maria-penha (+) & 15 & 2,933 & & & \\
\hline
\end{tabular}

Fonte: Dados da pesquisa, 2014. 
A principal característica do núcleo central é ser mais resistente a mudanças, bem como unificar e estabilizar a representação. Nele, existem elementos funcionais e normativos que lhe possibilitam desempenhar o papel avaliativo e pragmático, justificando os julgamentos de valor e direcionando as práticas específicas (11). Dessa forma, associados à caracterização descritiva e à inserção do objeto em estudo nas práticas sociais, identificam-se os elementos funcionais violência e violência-física. Quanto aos elementos normativos, verificou-se covardia e desrespeito, originados do sistema de valores dos indivíduos, "determinam os julgamentos e as tomadas de posição relativas ao objeto" (11).

Ainda referente ao núcleo central, verificou-se a presença das dimensões formadoras de uma representação social, o conceito, imagem e atitude (12). Assim, a dimensão atitudinal é verificada pelo julgamento da VDCM como uma covardia e desrespeito. Os termos violência e violência-física expressam o conceito que as discentes de enfermagem têm sobre a VDCM, o último evidencia também a dimensão imagética, demonstrando que as participantes destacam essa forma de VDCM das demais. Os termos dor e sofrimento caracterizam a esfera subjetiva da representação, enquanto sentimentos desencadeados pela ocorrência da VDCM.

Verifica-se que as discentes de enfermagem possuem uma representação estruturada, cujo núcleo central contém imagem, conceito e atitude. Ainda, trata-se de uma representação social com conotação negativa, uma vez que todos os elementos que compõem o núcleo central foram determinados pelas participantes como negativos. Destaca-se que no núcleo se identifica o conhecimento reificado, uma vez que as discentes reconhecem a existência de outras formas de violência, além da física, comumente abordada pela mídia.

A Lei $\mathrm{n}^{\mathbf{0}}$ 11.340, conhecida como Maria da Penha, prevê cinco formas de violência, quais sejam física, sexual, psicológica, patrimonial e moral (3). Pesquisa realizada com profissionais da USF evidenciou que há dificuldade em identificar as mulheres vítimas de violência, ocorrendo apenas quando se trata da forma física. As demais maneiras de manifestação não foram reconhecidas pelas profissionais (13). Outra pesquisa realizada entre profissionais da saúde e gestores municipais, a fim de identificar a representação da violência contra a mulher, encontrou como possíveis elementos centrais medo, álcool, sobrecarga de trabalho da mulher, desrespeito, agressão física e agressão (14).

Nos quadrantes superior e inferior direito se localiza a primeira e segunda periferia, respectivamente. São esses elementos que "estabelecem a interface entre o núcleo central e a realidade concreta na qual são elaboradas e funcionam as representações" (15). A primeira periferia deste estudo é formada pelos termos medo e submissão. Esses são sentimentos veiculados pela mídia como inibidores da denúncia, que levam a mulher a manter o relacionamento com o agressor. Assim, evidencia-se na representação dos discentes de enfermagem o conhecimento do senso comum.

Destaca-se que o termo medo é o mais frequente, apontando um sentimento da vítima ou da futura profissional em relação ao agressor. Nesse sentido, um estudo identificou que o sentimento de medo pode estar associado à mulher em situação de violência e ao profissional de saúde frente à problemática (14). Quanto à mulher, uma pesquisa realizada em Hong Kong identificou relatos de vítimas que viviam com medo de que o agressor pudesse matá-las ou fazer algo contra as filhas (16).

Um estudo desenvolvido com estudantes de enfermagem sobre a ocorrência da violência de gênero no namoro evidenciou que o medo é um sentimento comum entre elas, independente de ter sofrido agressão ou de se sentir agredida. Essas entrevistadas, ao se visualizarem, hipoteticamente, como membros de uma equipe, reconheceram que a violência de gênero deve ser abordada por profissionais especificamente treinados e 
que as barreiras para o reconhecimento, bem como para o tratamento do problema, provém da própria vítima (17).

O medo e a sensação de impotência diante dos agressores evidenciam a dominação masculina ainda presente em algumas culturas(14). Nesse sentido, outra pesquisa realizada com estudantes de enfermagem sobre violência no namoro concluiu que mulheres jovens são as principais vítimas e que é transversal a todas as raças, culturas, níveis socioeconômicos/educacionais, bem como tem raízes históricas e culturais. Dentre esses entrevistados, a principal forma de violência relatada foi a psicológica sob forma de perseguição. Os autores afirmaram que, por vezes, estar em relacionamentos violentos é aceito como normal, pois também ocorre entre outros casais de namorados (18).

No que se refere ao termo submissão, as discentes de enfermagem o qualificaram como negativo, sendo um sentimento que contribui para a continuidade da VDCM. Em um estudo sobre a representação da violência contra a mulher, essa foi qualificada como submissa e as motivações do agressor justificadas pelos termos cultura e machismo (14).

A segunda periferia é composta por elementos menos frequentes e evocados mais tardiamente, constitui a interface mais próxima da representação, com as práticas sociais (19). O termo vergonha foi evocado pelas discentes de enfermagem e pode se referir a mais um sentimento que inibe as vítimas de procurarem por apoio ou denunciarem seus agressores. Nesse sentido, uma pesquisa realizada com profissionais de saúde, dentre eles enfermeiros, verificou que, ao sofrem algum tipo de violência no ambiente de trabalho, eles não a relatam por medo ou vergonha. Esses entrevistados afirmaram que não há procedimentos específicos instituídos no serviço de saúde para uma comunicação oficial do ato violento, tão pouco programas, políticas, treinamentos ou formação para atuar nessas situações (20).

No quadrante inferior esquerdo, com baixa frequência e ordem de evocação menor que a média, encontram-se os elementos de contraste. Esses elementos possivelmente reforçam a primeira periferia e podem revelar a existência de um subgrupo minoritário que possui variações na sua representação (15). Tal variação não modifica a representação da totalidade dos informantes.

Neste estudo, identificou-se na zona de contraste os termos sofrimento, tristeza, machismo, crime, impunidade e maria-penha. Os dois primeiros reforçam a esfera sentimental, presente também na primeira periferia. A dimensão atitudinal pelas palavras machismo, crime e impunidade, as quais reforçam os termos covardia e desrespeito no núcleo central. Enfatiza-se o conhecimento reificado construído ao longo da graduação, através dos termos impunidade, crime e maria-penha. Destaca-se que, pelo termo maria-penha, único determinado positivamente, pode-se inferir a existência de um subgrupo dos discentes de enfermagem, possivelmente aquelas das séries finais por terem discutido a lei, representando assim a VDCM no respaldo legal que as vítimas possuem para romper com o ciclo da violência.

Por outro lado, com a ampla divulgação nas mídias escrita e falada, a Lei Maria da Penha tornou-se reconhecida pela população brasileira como uma ferramenta de enfrentamento à VDCM. Dessa forma, torna-se um conhecimento do senso comum, presente também na representação dos discentes. A referida lei instituiu medidas punitivas para o agressor como prisão preventiva, suspensão do porte de arma, afastamento do lar, proibição de aproximar-se da vítima, entre outras (3). Além da lei, outros serviços de proteção à vítima são veiculados na mídia, seja televisão, rádio, internet, revistas e jornais. Exemplo disso é a Central de Atendimento à Mulher (Ligue 180), que, para 62\% das vítimas usuárias do serviço, tornou-se conhecido pela mídia (4).

O termo impunidade em relação à VDCM também foi evocado em outra pesquisa, a qual se refere ao fato de as vítimas deixarem seus agressores livres de punição, algumas 
por não denunciarem; outras por retirarem a queixa (19). Quanto ao machismo, um estudo realizado com mulheres chinesas identificou o relato de uma vítima que era forçada a manter relações sexuais com seu marido, pois ele afirmava ser o dever como esposa (16).

A ocorrência da VDCM por motivos de gênero são descritas em outro estudo, no qual as vítimas suportavam repetidas agressões físicas por acreditarem que o marido tem o direito de bater na esposa quando ela queima a comida, argumenta com o marido, recusa-se a fazer sexo, negligencia os filhos e sai sem avisá-lo (21). Uma pesquisa realizada com o objetivo de identificar elementos que contribuem para o enfrentamento na percepção de profissionais da rede de serviços de atendimento às vítimas reforça que a violência contra a mulher tem raízes na desigualdade de gênero, reforçando a importância da articulação entre os serviços (22).

Devido à alta frequência com que foram evocados, alguns elementos constantes na periferia da representação podem ser considerados centrais (10). Dessa forma, vem sendo utilizado, de forma complementar, um segundo indicador de centralidade, a análise de similitude que verifica a "quantidade de laços ou conexões que um dado elemento mantém com outros elementos da representação" (8).

Verificando o grau de conexões dos elementos identificados como participantes da representação analisada, a árvore máxima (Figura 1) aponta como conexão mais forte $(0,12)$ a existente entre os termos violência e medo, sendo então os organizadores dos demais elementos da representação. O termo que mais estabeleceu conexões foi violência, identificado como central no quadro de quatro casas. A palavra medo, presente na primeira periferia, pela análise de similitude, pode ser considerada um elemento central.

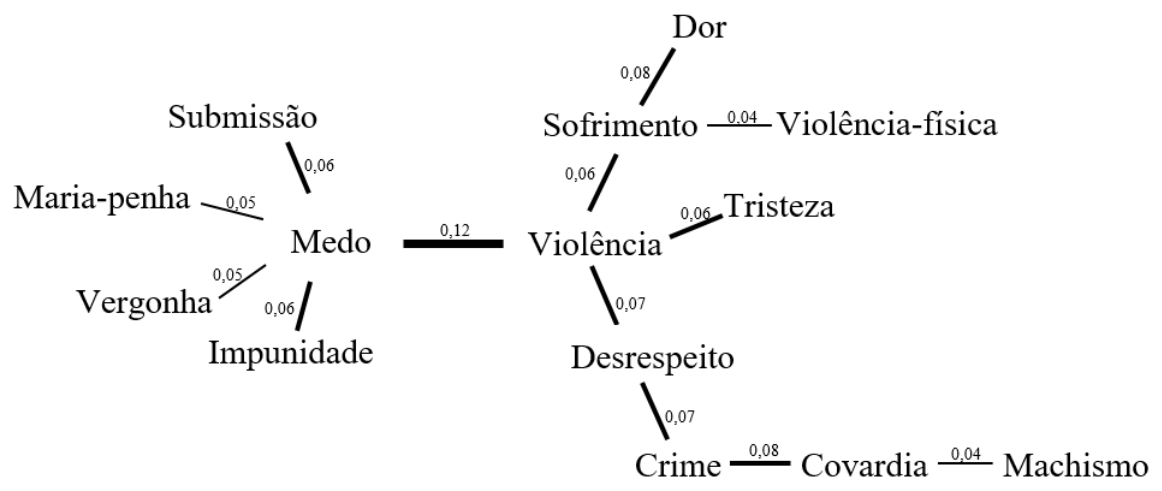

Figura 1. Árvore máxima resultante da análise de similitude da representação social dos discentes de enfermagem acerca da violência doméstica contra a mulher. Rio Grande, RS, 2014. Fonte: Dados da pesquisa, 2014.

Conectados ao termo violência, verifica-se a dimensão atitudinal da representação dos discentes acerca da VDCM, evidenciada pelas palavras desrespeito, crime, covardia e machismo. Observa-se a esfera sentimental através do termo tristeza que pode estar associado à discente em relação à VDCM ou ao reconhecimento de um sentimento da vítima. Os termos sofrimento e dor possivelmente indicam consequências da violência para a vítima, por outro lado violência-física, com baixo grau de conexidade, pode ser considerada causadora do sofrimento.

Destaca-se que a violência na forma física é a mais comumente lembrada, devido às marcas visíveis deixadas no corpo da vítima. No entanto, nem sempre é a mais corriqueira, 
como mostra um estudo realizado com mulheres africanas. Neste, verificou-se que $30,8 \%$ delas sofreram a violência emocional, 19,3\%, a sexual e 10,7\%, a física (23).

No lado oposto ao termo violência, encontra-se a esfera sentimental, identificada pelo elemento medo, o qual mantém conexidade com submissão, vergonha, maria-penha e impunidade. Movidas pelo medo, vergonha e submissão, as vítimas podem ter dificuldade de romper com os atos violentos, deixando de buscar por seus direitos e consequentemente o agressor acaba ficando impune.

Essas conexões se destacam por evidenciarem a realidade de muitos casos de VDCM, em que a vítima não denúncia o agressor ou quando o faz, acaba voltando atrás. Nesse sentido, um estudo realizado com os boletins de ocorrência de uma Delegacia Especializada no Atendimento às Mulheres identificou que a maioria das vítimas vinha sofrendo com a violência até tomar coragem para denunciar o agressor (24).

\section{Considerações finais}

A representação social da VDCM dos discentes de enfermagem é estruturada, uma vez que o núcleo central possui os elementos formadores de uma representação, os quais são o conceito, imagem e atitude. A representação da VDCM tem conotação negativa, pois todos os elementos no núcleo foram determinados pelos participantes como negativos.

O núcleo central possui ainda os elementos normativos e funcionais, indicados pelos termos covardia/desrespeito e violência/violência-física. Destaca-se a representação da VDCM pelo termo medo, mais frequente em todo o quadro de quatro casas e verificado pela análise de similitude como um possível elemento central da representação. Tal sentimento pode permear as decisões das vítimas e as ações dos futuros profissionais.

A possível existência de um subgrupo minoritário, formado pelas discentes das séries finais, é verificada pelo termo maria-penha, o qual foi o único do quadro de quatro casas determinado positivamente pelas participantes. Dessa forma, verifica-se que, embora a representação da VDCM entre discentes de enfermagem seja permeada pelo conhecimento do senso comum, o conhecimento reificado construído ao longo do curso de graduação em enfermagem se destaca pelos termos violência e violência-física que indicam a dimensão conceitual, bem como impunidade, crime e maria-penha que evidenciam o rompimento com a naturalização da ocorrência da VDCM.

Embora o objetivo da pesquisa de identificar a estrutura e conteúdo da representação da VDCM entre discentes de enfermagem tenha sido alcançado, os resultados constituem uma primeira análise de um grupo específico de futuros profissionais da área da saúde. Frente a essa limitação, torna-se necessário ampliar para outras instituições e até mesmo categorias profissionais.

Espera-se com a pesquisa que a representação social da VDCM oriente a ação acadêmica e profissional dos discentes de enfermagem e que as instituições de Ensino Superior incentivem a construção e o fortalecimento do conhecimento reificado ao longo do curso de graduação, por meio de debates e problematizações acerca da temática.

Conflito de interesses: Os autores declaram não haver conflito de interesses.

\section{Referências}

1. Who. Who report highlights violence against women as a 'global health problem of epidemic proportions'. [Internet]. 2013. [citado em 2015 Sept. 2]. Disponível em: http://www.who.int/mediacentre/news/releases/2013/violence_against_women_20130620/en/index.html 
2. Waiselfisz JJ. Mapa da Violência 2012, Atualização: homicídio de mulheres no Brasil. [Internet]. Flacso Brasil, 2012. [citado em 2017 Feb. 12]. Disponível em: http://mapadaviolencia.org.br/pdf2012/mapa2012_web.pdf.

3. Brasil. Lei n. 11.340 de 7 de agosto de 2006. Dispõe sobre a Lei Maria da Penha. [Internet]. 2006. [citado em 2017 Feb. 12]. Disponível em: http://www.planalto.gov.br/ccivil_03/_ato20042006/2006/lei/111340.htm.

4. Brasil. Balanço 2014 da Central de Atendimento à mulher. [Internet]. Secretaria de Políticas para as Mulheres Presidência da República. 2015. [citado em 2017 Mar. 09]. Disponível em: http://www.spm.gov.br/central-de-conteudos/publicacoes/publicacoes/2015/balanco180_2014versaoweb.pdf.

5. Pedrosa CM; Spink MJP. A Violência Contra Mulher no Cotidiano dos Serviços de Saúde: desafios para a formação médica. Saúde Soc 2011; 20 (1):124-35.

6. Vieira LB; Padoin SMM; Landerdahl MC. A percepção de profissionais da saúde de um hospital sobre a violência contra as mulheres. Rev Gaúcha Enferm 2009; 30 (4):609-16.

7. Brasil. Diretrizes Curriculares Nacionais dos Cursos de Graduação em Enfermagem, Medicina e Nutrição. [Internet] 2001. [citado em 2015 Mar. 17]. Disponível em: http://portal.mec.gov.br/dmdocuments/ces1133.pdf 2001.

8. Sá CP. Introdução. In: Sá CP. Núcleo central das representações sociais. Petrópolis: Vozes; 2002. p. 13-27.

9. Silva LA; Gomes AMT; Oliveira DC; Souza MGG. Social representations of aging in institutionalized psychiatric patients. Esc Anna Nery 2011; 15 (1):124-31.

10. Pontes APM; Oliveira DC; Gomes AMT. Os princípios do Sistema Único de Saúde estudados a partir da análise de similitude. Rev LatinoAm Enferm 2014; 22 (1):59-67.

11. Abric JC. Abordagem estrutural das representações sociais: desenvolvimentos recentes. In: Campos PHF, Loureiro MCS, organizadores. Representações Sociais e Práticas Educativas. Goiânia:UCG, 2003. p.36-57.

12. Paschoal EP; Espírito Santo CC; Gomes AMT; Santos EI; Oliveira DC; Pontes APM. Adherence to antiretroviral therapy and its representations for people living with HIV/AIDS. Esc Anna Nery. 2014;18(1):32-40.

13. Gomes NP; Silveira YM; Diniz NMF; Paixão GPN; Camargo CL; Gomes NR. Identification of violence in the conjugal relationship based on the family health strategy. Texto Contexto Enferm 2013; 22 (3):789-96.

14. Costa MC; Lopes MJM; Soares JSF. Social Representations of Violence Against Rural Women: Unveiling Senses In Multiple Views. Rev Esc Enferm USP 2014; 48 (2):214-22.

15. Oliveira DC; Marques SC; Gomes AMT; Teixeira MCTV. Análise das evocações livres: uma técnica de análise estrutural das representações sociais. In: Moreira, organizador. Perspectivas teóricometodológicas em Representações Sociais. João Pessoa: UFPE/ Editora Universitária, 2005. p.573-603.

16. Tiwari A; Cheung DST; Chan KL; Fong DYT; Yan ECW; Lam GLL et al. Intimate partner sexual aggression against Chinese women: a mixed methods study. [Internet]. BMC Womens Health 2014; 14:70. [citado em 2017 Mar. 15]. Disponível: https://www.ncbi.nlm.nih.gov/pubmed/24886374.

17. Díaz VG; Feito AF; Díaz FJR; González MLL; Díaz MDPM; Pérez AL. Violencia de género en estudiantes de enfermería durante sus relaciones de noviazgo. Atención primaria 2011; 45 (6):290-6.

18. Martins C; Gouveia A; Chaves M; Lourenço R; Marques S; Santos T. Dating violence and nursing student well-being. Atención Primaria 2014; 46 (5):129-34.

19. Silva CD; Gomes VLO; Oliveira DC; Marques SC; Fonseca AD; Martins SR. Representação social da violência doméstica contra a mulher entre Técnicos de Enfermagem e Agentes Comunitários. Rev Esc Enferm USP 2015; 49 (1):22-9.

20. Kitaneh M; Hamdan M. Workplace violence against physicians and nurses in Palestinian public hospitals: a cross-sectional study. [Internet]. BMC Health Serv Res 2012; 12(469). [citado em 2017 Apr. 17]. Disponível em: https://bmchealthservres.biomedcentral.com/articles/10.1186/1472-6963-12-469

21. Semahegn A; Belachew T; Abdulahi M. Domestic violence and its predictors among married women in reproductive age in Fagitalekoma Woreda, Awi zone, Amhara regional state, North Western Ethiopia. [Internet]. Reprod Health. 2013; 10:63. [citado em 2017 Apr. 17]. Disponível em: https://reproductivehealth-journal.biomedcentral.com/articles/10.1186/1742-4755-10-63. 
22. Gomes NP; Bomfim ANA; Diniz MF; Souza SS; Couto TM. Percepção dos profissionais da rede de serviços sobre o enfrentamento da violência contra a mulher. Rev enferm UERJ 2012; 20 (2):173-8.

23. Sigalla GN; Rasch V; Gammeltoft T; Meyrowitsch DW; Rogathi J; Manongi R, et al. Social support and intimate partner violence during pregnancy among women attending antenatal care in Moshi Municipality, Northern Tanzania. [Internet]. BMC Public Health. 2017; 17:240. [citado em 2017 Apr. 18]. Disponível em: https://bmcpublichealth.biomedcentral.com/articles/10.1186/s12889-017-4157-3.

24. Acosta DF, Gomes VLO, Barlem ELD. Perfil das ocorrências policiais de violência contra a mulher. Acta paul enferm 2013; 26 (6):547-53. 